\title{
Review of: "Possible poriferan body fossils in early Neoproterozoic microbial reefs"
}

\author{
George Mikhailovsky
}

Potential competing interests: The author(s) declared that no potential competing interests exist.

The article by Elizabeth Turner addresses a very interesting, important and still under-explored problem of the emergence of the first multicellular eukaryotes, as well as when and where it happened.

She analyzed the petrographically identical vermiform microstructures of the reefs dating back 890 million years and identified them as fossilized tissues of keratosis sponges. This time corresponds to Tonian period of Neoproterozoic era and about 350 million years earlier than the next-youngest undisputed sponge body fossils in Cambrian period of Paleozoic.

The author quite reasonably believes that a sufficient level of oxygen in the atmosphere is required for the emergence of multicellularity, whereas before the Neoproterozoic oxygenation event, which began about 800 million years ago, this level was very low. However, reefs built by filamentous photosynthetic cyanobacteria may contain unique microniches with much higher oxygen concentration.

According to supposition of Dr. Turner, the environment in these microniches could be suitable enough for the emergence of eukaryotic multicellular organisms such as sponges. If this assumption is true, and the vermiform microstructures are in fact the fossilized tissue of keratose sponges, they would represent the oldest body-fossil evidence of animals known to date; moreover, these animals emerged before the Neoproterozoic oxygenation and survived through all the glacial episodes of the Cryogenian period. And this assumption look quite reasonable.

The article is well written and presents the state of the art on non-spicules sponges found in carbonates in the fossil record. The description of taphonomic processes is also given at a completely modern level. The referenced literature covers all recently published articles on a given topic. 